\title{
Body Cavity Primary Effusion Lymphoma
}

National Cancer Institute

\section{Source}

National Cancer Institute. Body Cavity Primary Effusion Lymphoma. NCI Thesaurus.

Code C150407.

A large B-cell lymphoma presenting as a serous effusion without detectable tumor masses. It is universally associated with human herpes virus 8 (HHV8), also called Kaposi sarcoma-associated herpesvirus. It mostly occurs in the setting of immunodeficiency. The most common sites of involvement are the pleural, pericardial, and peritoneal cavities. (WHO 2017) 